\title{
USO DO DESIGN THINKING PARA APOIAR O DESENVOLVIMENTO DE UM APLICATIVO PARA A AGROINDÚSTRIA DE SOJA
}

Arthur Henrique Moreira (arthurhq1@hotmail.com) - Departamento de Engenharia de Produção, Universidade Federal de Uberlândia (UFU).

Eugênio Pacceli Costa (eugenio@ufu.br) - Departamento de Engenharia de Produção, Universidade Federal de Uberlândia (UFU).

Marcus Vinícius Ribeiro Machado (mvrmachado@ufu.br) - Departamento de Engenharia de Produção, Universidade Federal de Uberlândia (UFU).

Luís Fernando Magnanini de Almeida (almeida@ufu.br) - Departamento de Engenharia de Produção, Universidade Federal de Uberlândia (UFU).

\section{RESUMO}

O trabalho apresenta o uso do Design Thinking para apoiar o desenvolvimento de um aplicativo para a agroindústria de soja, o qual na sua versão piloto engloba as atividades de housekeeping no processo de esmagamento/ moagem. Esse aplicativo é o primeiro dentro de uma iniciativa de digitalização, devendo ser posteriormente melhorado e integrado a outros sistemas de informação da empresa. A escolha do Design Thinking para apoiar esse desenvolvimento se deve a necessidade de se definir as necessidades das diferentes partes interessadas e usuários de modo profundo, visto que são perfis muito distintos, tanto com relação a familiaridade com o uso de tecnologias digitais, quanto com relação ao grau de instrução formal. Também foi necessário adequar o aplicativo as particularidades da agroindústria, dentre elas, dificuldades de conexão, riscos de acidentes, partículas suspensas no ambiente, assim como as exigências de auditoria. Como principais resultados, constatou-se que o aplicativo atingiu os objetivos iniciais, sendo de uso intuitivo, com ampla aceitação pelos usuários e se adequando ao ambiente agroindustrial, demonstrando a viabilidade da continuidade dessa iniciativa.

Palavras-chave: Design Thinking; digitalização; esmagamento de soja; Power Apps; agroindústria. 


\section{INTRODUÇÃO}

O aumento da população mundial leva a uma maior necessidade de produção de alimentos, com projeções que estimam um número superior à 9,7 bilhões de pessoas no mundo em 2050 (ONU, 2019). A soja tem papel de destaque na alimentação, sendo a principal fonte de proteína para alimentação animal e o seu óleo é o segundo mais consumido no mundo, ficando atrás apenas para o óleo de palma (LEMOS et al, 2017).

Brasil é um dos principais produtores de grãos, sendo que na safra de soja de 2016/2017, a cultura ocupou uma área de 33,89 milhões de hectares, totalizando em uma produção e 113,92 milhões de toneladas e a sua produtividade média foi de $3.362 \mathrm{~kg}$ por hectare (BALBINOT JUNIOR; HIRAKURI; FRANCHINI; DEBIASI; RIBEIRO, 2017). O país se torna cada vez mais importante quando considerada essa cultura, tendo sido o maior produtor e exportador mundial quando considerada a safra de 2020, com participação de $37,5 \%$ e 50,3\%, respectivamente (USDA, 2021).

Dois fatores fizeram com que essa oleaginosa se consolidasse no país, sendo o primeiro a capacidade dela de ser utilizada como uma alternativa muito eficiente no cultivo durante o verão, além do aumento da demanda por farelo de soja devido à crescente produção de suínos e aves (EMBRAPA, 2014). O investimento e avanço tecnológico voltado para o campo e pesquisas sobre seu melhoramento genético que possibilitaram a expansão do seu cultivo para diversas localidades, com variadas latitudes, climas e solo aumentando em muito a área territorial plantada e a produtividade do negócio também. (EMBRAPA, 2014).

Além da expansão no cultivo, também houve um crescimento da moagem de soja nas fábricas situadas no Brasil, tendo se multiplicado em 5 vezes o volume que passa por esse processo desde os anos 1980 (USDA, 2021). Contudo, apesar do investimento em tecnologia e produtividade no campo, ainda há amplo espaço para evolução e aumento de produtividade nas agroindústrias, especialmente no que diz respeito a digitalização.

É nesse contexto que trabalho se insere, sendo parte do projeto piloto de um programa de digitalização mais amplo da empresa estudada. O objetivo do trabalho é utilizar o Design Thinking para apoiar o desenvolvimento de um aplicativo para uma agroindústria de processamento de soja.

A escolha pela utilização do Design Thinking se deve a uma gama de fatores dentro do projeto estudado. O primeiro deles é o perfil distinto dos usuários do aplicativo. Se por um lado, os tomadores de decisão (gestores e supervisores) têm uma familiaridade com o uso de tecnologias digitais e elevado grau de instrução formal, os operadores, por outro lado, 
possuem, em sua maioria, uma baixa escolaridade e dificuldade com o uso de tecnologias digitais.

Além dos diferentes perfis, o ambiente agroindustrial possui uma série de particularidades, tanto com relação aos procedimentos para garantir a segurança alimentar do produto resultante, quanto quando considerados aspectos como dificuldades de conexão, riscos de acidentes, partículas suspensas no ambiente e exigências de autoria.

Desse modo, o aplicativo piloto desenvolvido teve algumas metas a serem atingidas, como a diminuição do desperdício com a impressão de papel, a sistematização das informações para fins de auditoria e ter um alto índice de aceitação pelos operadores, visto que seu sucesso poderia diminuir a resistência à mudança com relação ao programa mais amplo.

Para a versão piloto abordada no presente trabalho foi escolhido a digitalização do caderno de atividades de housekeeping dentro do processo de moagem de soja, pois ele é um conjunto de atividades de manutenção e limpeza realizado diariamente, além por ser digitalizado de forma relativamente simples.

\section{REVISÃO TEÓRICA}

O entendimento do processamento do grão de soja é constituído por diversas etapas desde a chegada do grão in natura até a obtenção dos produtos derivados, sendo eles o óleo bruto e refinado, o farelo moído e peletizado e a casca moída e peletizada. Pode-se separar as etapas em: Recebimento do grão; Armazenamento da soja; Preparação inicial; Extração do óleo bruto; Processo de refinação do óleo bruto.

O processo tem início com o recebimento das sementes oleaginosas vindas dos campos e armazéns e logo que chega na fábrica processadora de soja o caminhão é pesado. É feita a classificação do produto por amostragem para averiguar as características nutricionais e físicas, como por exemplo a fibra, proteína, umidade, impurezas etc., a fim de definir para qual silo será encaminhado caso o lote seja aprovado (CUSTÓDIO, 2003).

Após o recebimento a soja precisa ser armazenada, sendo então encaminhada para os graneleiros ou silos, com o intuito de ter uma melhor conservação e descansar, para que possa ter uma eficiência melhor no processo. Caso a soja esteja com um percentual de umidade elevado, ela deve passar pela área da secagem primeiro até atingir índices menores que 12\% 
de umidade para evitar maiores problemas ao ser armazenada, como pragas, fungos e outras deteriorações causadas pela umidade (CUSTÓDIO, 2003).

A soja descansada é enviada então para a preparação, na qual ocorrem vários procedimentos a fim de garantir que os grãos sejam transformados em flocos. Entre as etapas têm-se a de limpeza; secagem, que também é dita como ressecagem; a quebra dos grãos; dehulling (separação casca e quebrado); condicionamento e laminação (CUSTÓDIO, 2003).

Tendo transformado os quebrados em flocos após a laminação, esses são enviados para a área da extração para que se possa fazer a separação do óleo da fase sólida e consequentemente obter o farelo de soja. Existem três meios para fazer esse processo, sendo eles: prensagem mecânica, extração por solvente e processo misto (PARAÍSO, 2001).

Terminada a etapa de extração, tem-se como saída do extrator a micela, que é o líquido homogêneo de óleo-solvente e a torta, a qual é o conjunto de farelo e solvente, chamado também de farelo branco. Custódio (2003) afirma que após a descarga desses produtos, eles devem passar por processos para que seja removido o residual de hexano contido nesses produtos obtidos e para que possa reaproveitar o hexano para lavagens dos flocos novamente. O farelo branco segue para o dessolventizador-tostador (DT) e a micela segue para o sistema de destilação.

\subsection{Design Thinking}

O Design Thinking (DT) surgiu na década de 1980 nos livros de design os quais retratavam a forma que os designers pensavam e criavam, entretanto, foi somente em 1991 que o DT teve o seu desenvolvimento impulsionado e isso devido a fundação da IDEO, uma empresa norte-americana de Design, voltada para a criação de produtos inovadores por meio de uma metodologia própria, com base no modo de pensar e agir dos designers (NITZSCHE, 2012).

O DT se tornou popular devido uma das suas principais diferenças e característica que os designers possuem, que que geralmente se baseiam no raciocínio indutivo ou dedutivo (DORST, 2011). Entretanto, os designers usualmente solucionam os problemas de forma única, pois utilizam o raciocínio abdutivo, no qual se tem a criação de valor e não gera respostas definitivas, verdades, entretanto, apresenta uma variedade de possíveis respostas e ideias (RYLANDER, 2009). 
Na prática, o que os designers fazem de diferente ao propor em uma solução para o problema é iniciar pensando no que se deseja obter, para que dessa forma ele tenha uma ampla liberdade no processo de solução, já que ele necessita criar não somente a resposta para o problema, mas também o caminho para chegar até essa resposta, o que possibilita e gera uma variedade de respostas e caminhos para um mesmo problema (DORST, 2011).

O Design Thinking só pode ser implementado de forma assertiva caso o time composto para a resolução do problema tenha determinadas características e estejam alinhadas com o perfil adequado de um bom design thinker, como: ter empatia, olhar o problema por diferentes pontos de vista, sempre colocar a pessoa no centro da solução, ser otimista, experimentador, colaborador, capaz de se conectar e transmitir seus pensamentos e ideias, assim como estar aberto a considerar a opinião de especialistas de diferentes áreas, além de possuir um pensamento integrador (BROWN, 2008).

Para Brown (2008), o Design Thinking tem em sua metodologia 3 etapas essenciais: a inspiração, idealização e implementação. A etapa de inspiração busca a exploração e identificação do problema que se deseja solucionar, ao tempo que são coletados e levantados o máximo de informações possível, insights e oportunidades por meio do ponto de vista focado no ser humano, ou seja, de forma empática. Já a etapa de idealização é a em que se inicia a resolução do problema, com a criação e testes de ideias que são plausíveis de ter um bom resultado na solução do problema, fazendo uso das informações levantadas na etapa anterior, refinando e reduzindo as oportunidades e as ideias a fim de ser crítico em relação as que sejam exequíveis, financeiramente econômicas e desejáveis. Por fim, a etapa implementação é feita por meio da prototipagem que permite avaliar e analisar o que está bom e o que precisa ser alterado de acordo com as opiniões e sugestões dos usuários (BROWN, 2008). Além do método, o design thinking geralmente utiliza-se de ferramentas para permitir o entendimento e criação, como: o design briefing (VINICIUS, 2017), a criação de personas (SIQUEIRA, 2020), o mapa de empatia (CAMPESE; VANEGAS, da COSTA, 2018), dentre outras.

\section{METODOLOGIA}

A natureza deste trabalho é considerada pesquisa aplicada (FIORI; BEZERRA, 2018), com abordagem qualitativa (GONZALES et al., 2018) e descritivo (SILVA et al., 2016). O método de pesquisa empregado foi a pesquisa-ação, pois é uma pesquisa social com base, 
sendo a sua concepção e realização estreitamente associada com uma ação ou com a resolução do problema proposto. Além disso, não só os pesquisadores, mas também os participantes representativos da situação ou do problema estão envolvidos na pesquisa, colaborando ou participando para juntos buscarem a solução (THIOLLENT, 2007).

Segundo West-Brook (1995), a pesquisa-ação se assemelha com o estudo de caso, com a diferença de que a pesquisa-ação interfere no ambiente ou objeto de estudo juntamente com os participantes da ação, de forma colaborativa, com o intuito de resolver um determinado problema e contribuir para a base do conhecimento.

A coleta de dados iniciou-se por meio da observação do operador trabalhando, já que esta é uma das características principais da primeira etapa do design thinking, observar e imergir no "habitat deles" a fim de levantar melhores informações e ideias sobre o que poderia ser feito para solucionar o problema, sempre com foco no ser humano, suas preferências, suas limitações. Além disso, foi realizada a coleta de dados por meio de entrevistas não estruturadas, na qual o pesquisador se atentou muito a escuta e as respostas dos operadores para que fosse tirado o melhor proveito possível, buscando sempre compreender suas ideias e desejos.

Ainda na coleta de dados, foram observados e consultados os cadernos utilizados pelos operadores a fim de melhor entender os dados e informações coletados, seu impacto no processo e seu uso, por meio da análise documental, sendo de grande valia para o desenvolvimento deste trabalho, visto que a ideia era digitalizar esses cadernos e posteriormente analisar a eficácia da solução proposta, como a aceitação dos operadores, a redução do papel utilizado para impressão dos cadernos e adequação a normas de auditoria.

Após a imersão inicial, sendo ela uma atividade da primeira parte do design thinking (inspiração), foi possível analisar os dados e utilizar a ferramenta do design briefing, com intuito de entender o que os envolvidos desejavam, os potenciais benefícios e permitir a criação da persona para que se pudesse pensar em soluções específicas para clientes (operadores e tomadores de decisão). Também foi utilizado o mapa de empatia para entender o que os operadores sentiam, visto que era a parte interessada que poderia apresentar maior resistência. Dado o número pequeno de tomadores de decisão e auditores, suas necessidades e anseios foram identificadas durante o levantamento de requisitos, por meio de conversas individuais.

Já na etapa de idealização foi utilizado brainstorming com a equipe de desenvolvimento do software e especialistas nos sistemas de informação da empresa, a fim de 
buscar a melhor forma de estruturar, criar e implantar uma versão piloto da solução. Por fim, na fase de prototipagem foi criado a versão piloto e colocada em operação dentro da atividade de housekeeping, dentro do processo de moagem, assim como foram coletadas as impressões dos usuários (operadores e tomadores de decisão), por meio de entrevistas semiestruturadas.

\section{RESULTADOS E DISCUSSÕES}

A empresa estudada atua há mais de 155 anos no agronegócio, oferecendo principalmente produtos e serviços alimentícios, agrícolas e industriais para todo o mundo. $\mathrm{Na}$ agricultura adquire, processa e distribui grãos e outras commodities tanto para o consumo humano como o animal. Busca ainda aumentar a produtividade dos seus próprios negócios e de seus parceiros, realizando treinamentos aos produtores, para que possam cultivar de forma mais sustentável e produtiva, além de oferecer tecnologia para que os grãos possam ser cultivados independentemente do clima, contribuindo para a expansão territorial disponível para plantio.

\subsection{Problemática e utilização do Design Thinking}

No início do estudo, os operadores relatavam todas as informações importantes para o processo apenas em cadernos físicos, de forma manual, tornando os dados difíceis para serem analisados e, muitas vezes, ocorrendo a perda desses cadernos. Outra preocupação é o fato de a impressão gerar um impacto tanto financeiro como ambiental, quando considerado a quantidade de papel e tinta consumidas, além de ser ineficiente, requerendo tempo dos gestores e supervisores para assinarem esses cadernos, certificando que os operadores realizam de fato a tarefa/atividade, assim como seu armazenamento e a necessidade de transcrever esses dados para realização de análises mais complexas.

A partir da problemática da empresa, iniciou-se um programa de digitalização de todos os cadernos utilizados nas áreas produtivas pelos operadores. Por se tratar de uma forma nova de realizar uma atividade já executada pelos operadores há muitos anos, além da preocupação de que a baixa instrução e pouca familiaridade com ferramentas digitais por parte dos operadores pudesse gerar alguma resistência a mudança, decidiu-se utilizar o design thinking para que se pudesse entregar um resultado de forma rápida, iterativa e com amplo envolvimento dos operadores. Para o projeto piloto foi escolhida a atividade de housekeeping, dentro do processo de moagem, a qual é abordado nesse trabalho. 


\subsubsection{Inspiração}

Primeiramente, foi necessário compreender o contexto e a rotina dos operadores com os cadernos, além de identificar as atividades realizadas e as informações importantes. Para isso, optou-se por acompanhar o trabalho dos operadores e a sua vivência no dia a dia

Logo, realizou-se uma imersão de aproximadamente duas semanas junto os operadores, tanto observando o trabalho, como em conversas informais e, até mesmo, realizando algumas das atividades a serem digitalizadas, de modo a entender a procedência dos dados e informações e qual era o intuito de armazená-las no caderno.

Também foram realizadas reuniões e conversas para que pudesse compreender a dinâmica e o envolvimento dos gestores e supervisores em relação a esses cadernos utilizados, visto que as informações contidas em algum deles podem ser importantes para um processo de tomada de decisão, monitoramento e controle, auditoria, além da obrigatoriedade dos gestores em assinarem os cadernos validando as ações realizadas. O Quadro 1 apresenta o design briefing do trabalho.

QUADRO 1 - Design Briefing do projeto. Fonte: Autoria própria. 


\begin{tabular}{|c|c|}
\hline \multicolumn{2}{|c|}{ Design Briefing } \\
\hline Desafio & Beneficiário \\
\hline $\begin{array}{l}\text { Por meio de tecnologia e inovação, } \\
\text { desenvolver/utilizar uma nova forma para a } \\
\text { inserção de informaçōes geradas no campo e por } \\
\text { determinados equipamentos, digitalizando esse } \\
\text { processo e dados, otimizando o tempo dos } \\
\text { operadores, reduzindo a quantidade de papel } \\
\text { impresso, garantindo um melhor gerenciamento e } \\
\text { uso dessas informações. }\end{array}$ & $\begin{array}{l}\text { Operadores, visto a maior facilidade na inserção de } \\
\text { dados, principalmente daqueles que estão no } \\
\text { campo; gestores e supervisores, já que poderão } \\
\text { aproveitar essas informações com o intuito de obter } \\
\text { um processo/produto com melhores características, } \\
\text { além de redução de custos; auditores, pois fará com } \\
\text { que a forma de verificação para eles será mais fäcil } \\
\text { e rápida. }\end{array}$ \\
\hline \multicolumn{2}{|r|}{ Restriçōes } \\
\hline \multicolumn{2}{|c|}{$\begin{array}{l}\text { Tecnologia utilizada, especialmente para os operadores devido a sua baixa escolaridade e intimidade com } \\
\text { determinadas tecnologias; responsáveis pela execução do projeto, já que em sua maioria não dominavam } \\
\text { o desenvolvimento de aplicativos; baixo orçamento; tempo para execução do projeto; necessidade de } \\
\text { adequação às diferentes fäbricas do grupo. }\end{array}$} \\
\hline O que já sabemos? & $\begin{array}{c}\text { Stakeholders } \\
\end{array}$ \\
\hline $\begin{array}{l}\text { Todas as informações inseridas, de onde elas vêm, } \\
\text { para que servem, o que elas impactam, quem são } \\
\text { responsáveis pelo seu preenchimento, qual a } \\
\text { frequência em que são geradas e preenchidas no } \\
\text { caderno, quem se beneficia com esses dados. } \\
\text { Sabemos também a importância desses dados para } \\
\text { cada stakeholder, quais as suas dificuldades em } \\
\text { relação a mudanças no processo e no trabalho, } \\
\text { especialmente as que envolvam novas tecnologias. }\end{array}$ & $\begin{array}{l}\text { Operadores, gestores, supervisores, auditores, } \\
\text { equipe de desenvolvimento, engenheiro de } \\
\text { melhoria continua, engenheiro de processo. }\end{array}$ \\
\hline Resultados esperados & Métricas \\
\hline $\begin{array}{l}\text { Entregar para os operadores uma forma/plataforma } \\
\text { que seja possivel o inserir de todas as informações } \\
\text { contidas nos cadernos de forma făcil e rápida; } \\
\text { economia de papel e adequação à auditoria }\end{array}$ & $\begin{array}{l}\text { Feedback dos stakeholders, principalmente os } \\
\text { operadores; tempo para execução e implementação } \\
\text { do projeto; aderência a solução implementada. }\end{array}$ \\
\hline
\end{tabular}

Após a construção do Design Briefing foi então realizado a definição da persona para o principal público-alvo, os operadores conforme apresentados no Quadro 2. Optou-se por não criar personas para os outros stakeholders, visto que pelo seu número pequeno, foi possível contemplar as demandas dentro dos levantamentos dos requisitos de desenvolvimento.

QUADRO 2 - Persona do operador. Fonte: Autoria própria. 


\begin{tabular}{|c|c|}
\hline \multicolumn{2}{|c|}{ Persona } \\
\hline Perfil & Sonhos e Aspiraçoes \\
\hline $\begin{array}{l}\text { Homem, } 37 \text { anos, casado, com filhos com idades } \\
\text { entre } 1 \text { a } 17 \text { anos, baixa escolaridade, sendo o } \\
\text { ensino médio a predominante, pouco conhecimento } \\
\text { e habilidades com tecnologia (celulares, } \\
\text { computadores, etc.), mentalidade fixa, baixa } \\
\text { flexibilidade para mudanças; gosto por esportes, } \\
\text { principalmente futebol; gosto por festas, bebidas e } \\
\text { passar o tempo livre se entretendo; interesse pela } \\
\text { parte mecânica dos equipamentos e pelas } \\
\text { caracteristicas e parâmetros que influenciam o } \\
\text { processo; alto consumo de informaçôes por redes } \\
\text { sociais e televisão; forte influência de amigos e } \\
\text { familias em suas decisões. }\end{array}$ & $\begin{array}{l}\text { Operadores sonham em ajudar com o seu } \\
\text { conhecimento e experiência para o } \\
\text { desenvolvimento de melhorias e soluções para } \\
\text { diversos problemas; menos atividades repetitivas e } \\
\text { fisicas; maior valorização pelo seu trabalho e por } \\
\text { suas ideias; melhor remuneração; maior } \\
\text { reconhecimento e tempo coma familia; saúde fisica } \\
\text { melhor com a diminuição do esforço no trabalho; } \\
\text { viagens para cidades turísticas; formação } \\
\text { acadêtmica de seus filhos; boas condições } \\
\text { financeiras para sua familia; aposentar com certa } \\
\text { estabilidade; casa e carros próprios. }\end{array}$ \\
\hline Expectativa & Dores \\
\hline $\begin{array}{l}\text { Redução da necessidade de preenc } \\
\text { cadernos; fácil e intuitiva solu } \\
\text { visualização do histórico de dados } \\
\text { gráficos, tabelas com filtros e ordenac }\end{array}$ & $\begin{array}{l}\text { Cansaço por esforço físico e má qualidade do sono; } \\
\text { tédio por precisar preencher mesmas informaçôs } \\
\text { todos os dias e por não ter responsabilidades que o } \\
\text { desafiem; rotina cansativa e enjoativa. }\end{array}$ \\
\hline
\end{tabular}

Por fim, realizou-se o mapa de empatia, (Figura 1), pois foi constatado o receio dos operadores em fornecerem feedbacks reais e completos pela forma histórica de como essas necessidades foram tratadas, muitas vezes sendo ignoradas ou consideradas "muito simples".

\section{Mapa de Empatia}

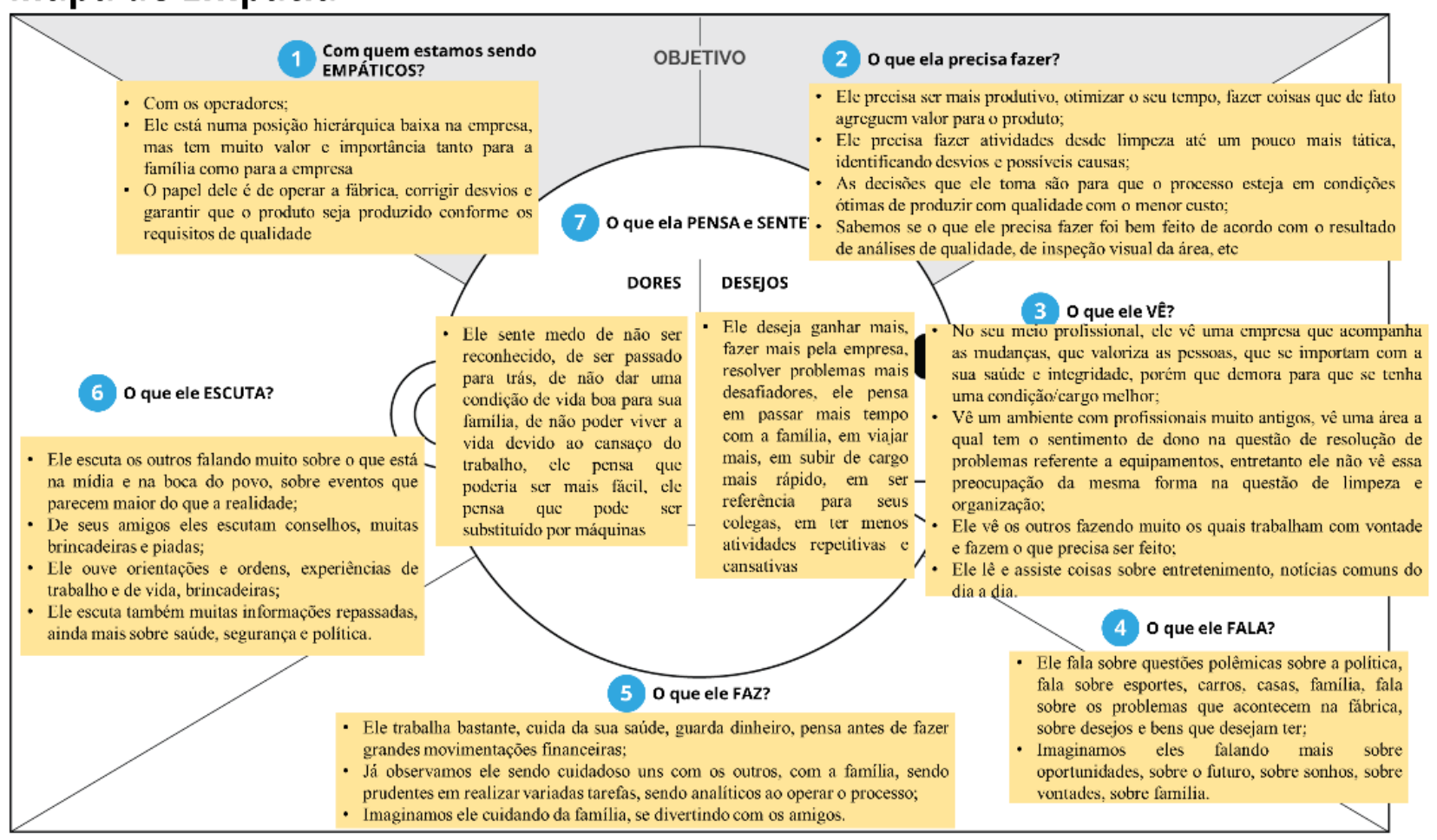

FIGURA 1 - Mapa de empatia. Fonte: Autoria própria.

\subsubsection{Idealização}


Foram realizadas reuniões, brainstorming, com o time responsável pelo desenvolvimento do projeto, junto do especialista em automação e outros que trabalham com tecnologia aplicada, principalmente na parte de programação, softwares e banco de dados. Com todas as informações sobre os cadernos, o brainstorming iniciou buscando reunir todas as ideias possíveis para viabilizar a digitalização dessas informações. Entre as que se destacaram estão: Excel® com VBA, Microsoft Forms ${ }^{\circledR}$, Power Apps ${ }^{\circledR}$. Após esse primeiro levantamento, foi feita a discussão sobre as alternativas, escolhendo-se o Power Apps ${ }^{\circledR}$.

Após a escolha, treinou-se a equipe de desenvolvimento e realizadas novas reuniões apenas com os desenvolvedores, nas quais foram discutidas questões como: Qual o melhor banco de dados a ser utilizado? Qual a forma de operacionalizar o banco de dados? O Aplicativo seria para celular ou tablet? Qual o melhor layout e disposição das funções no aplicativo para ajudar a operação, deixando-o intuitivo e fácil de usar? Qual seria o fluxo de informações? A ideia geral do aplicativo e o fluxograma de informações está ilustrado na Figura 2.

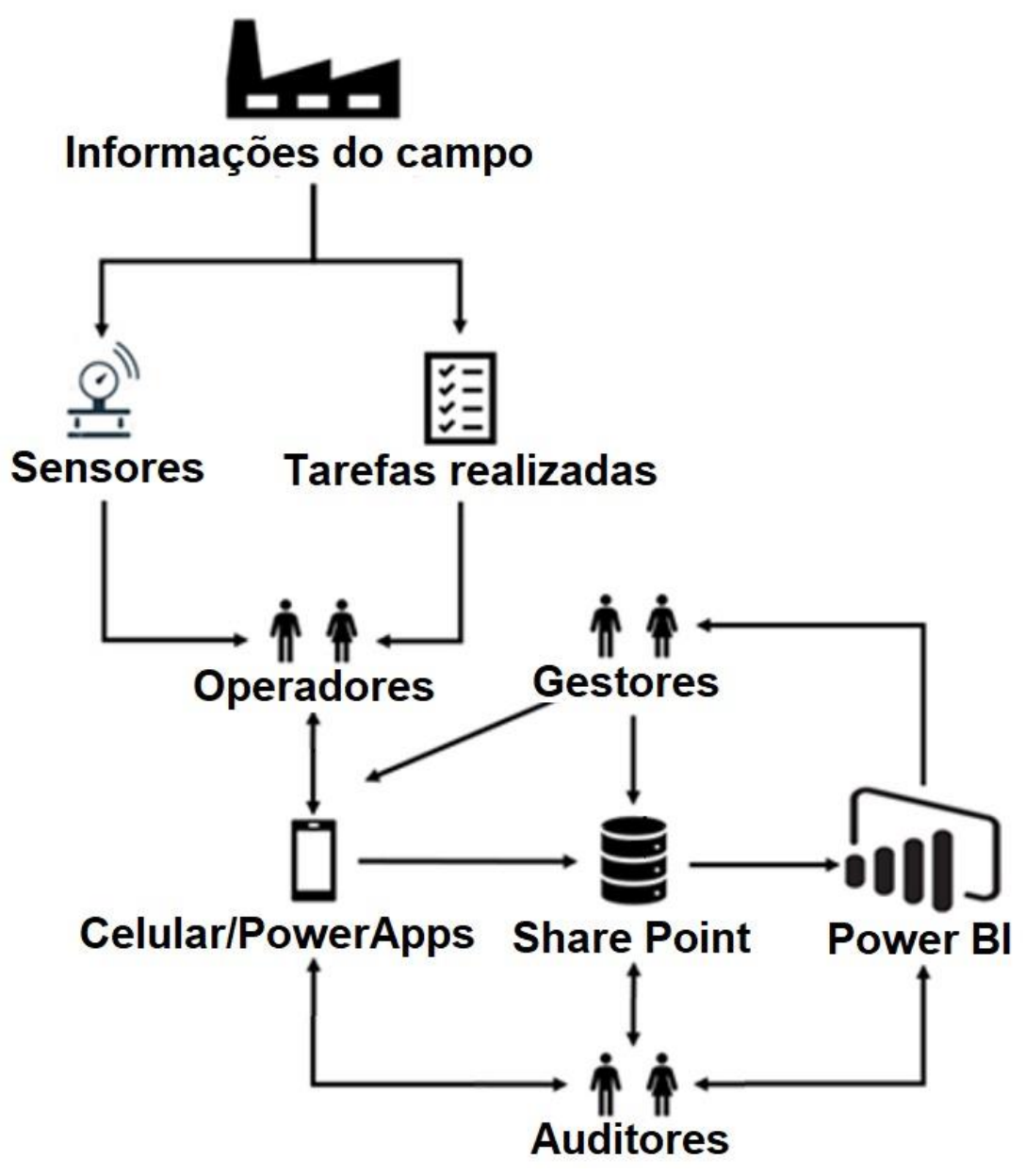

FIGURA 2 - Fluxograma de informações para o aplicativo. Fonte: Autoria própria. 


\subsubsection{Prototipação}

Após apresentação e aprovação dos gerentes e demais interessados, foi elaborado um protótipo apresentado em um fórum no qual os gerentes e supervisores de todas as plantas de soja da América do Sul participavam, tendo sido bem-visto e elogiado. A Figura 3 traz algumas telas do aplicativo desenvolvido.

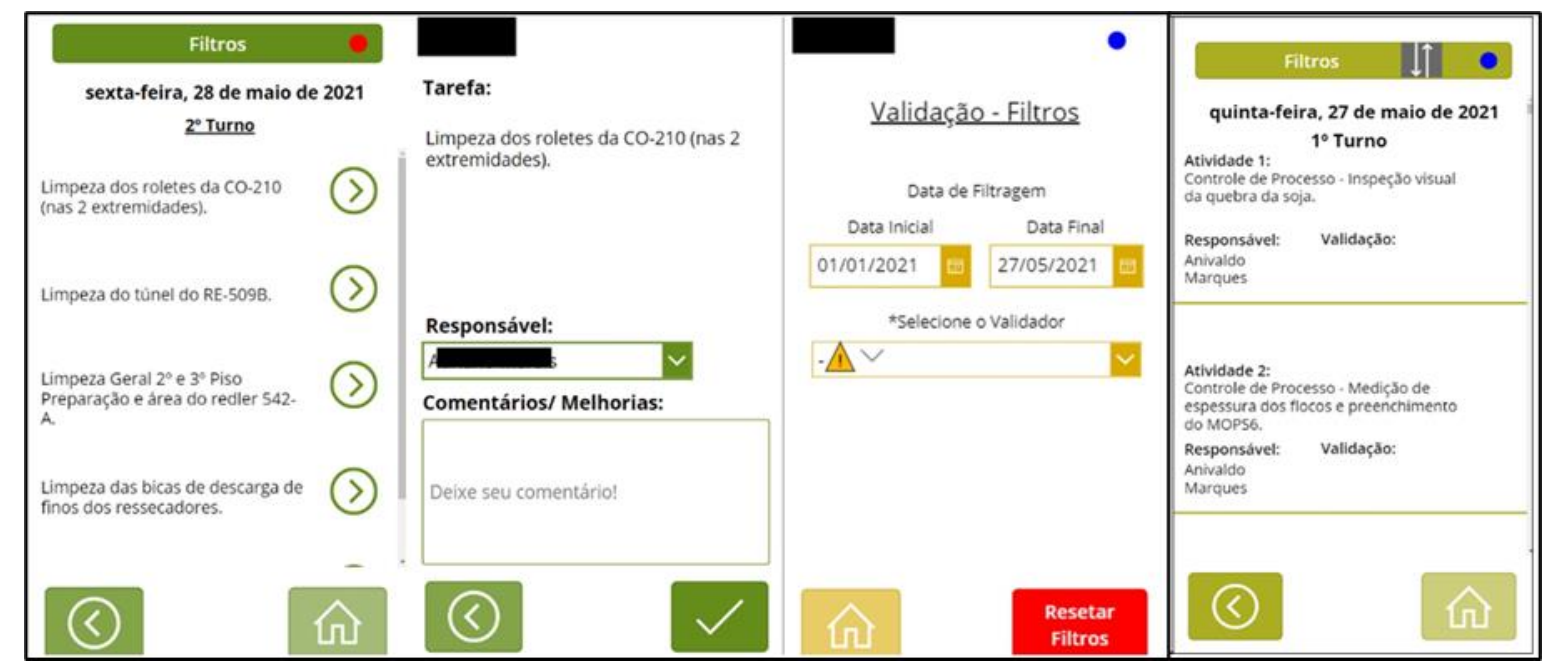

FIGURA 3 - Telas do aplicativo. Fonte: Autoria própria.

Após demonstração validada, passou-se ao treinamento dos operadores. Ressalta-se que não houve dificuldades nessa etapa, visto que o aplicativo fornecia um layout amigável e manteve os campos a serem preenchidos, apenas sendo realizado esse preenchimento de forma digital, sendo o treinamento baseado na técnica de storytelling, com a narrativa escrita com base nas informações obtidas na fase de imersão.

Após esse treinamento foram definidos cenários para a avaliação do protótipo, com o cenário bom definido como aquele que os operadores aceitariam a adotariam a solução proposta, preferindo o seu uso aos cadernos físicos. Já por parte dos gestores, no melhor cenário haveria uma verificação mais rápida das informações e considerariam o aplicativo mais prático e visual. O cenário intermediário era o que os operadores aderissem à solução, contudo, com receio de utilizá-la, apresentando resistência a remoção do caderno da sala de controle. Nesse cenário, os gerentes não apontariam diferenças substanciais entre o aplicativo e o caderno físico. Por fim, no pior cenário, os operadores apresentariam alta resistência a adoção do aplicativo, não adotando seu uso e os gerentes o considerariam inaceitável, visto que "mais atrapalha que ajuda". 
Definidos os cenários, o aplicativo foi colocado em operação obtendo uma aceitação satisfatória, visto que todos os vinte operadores não apresentaram dificuldade no seu uso, inclusive superando as expectativas, dado que os próprios operadores do primeiro turno que utilizou o aplicativo mostraram e ensinaram os operadores do turno seguinte, mesmo antes do treinamento formal. Os gestores também aprovaram a mudança, inclusive solicitando a incorporação de novas funcionalidades e a digitalização de novos cadernos. Com o uso mais intenso do aplicativo, será possível encontrar novos pontos de melhorias a serem tratados nas próximas fases do programa de digitalização.

\section{CONCLUSÕES}

O uso design thinking conseguiu apoiar o desenvolvimento de um aplicativo para a agroindústria, evidenciando a sua aplicabilidade nessa área. Mesmo com apenas o protótipo em operação, foi constatada a alta adesão ao uso do aplicativo e o relato dos gestores com relação a diminuição do tempo para validação das atividades realizadas. Um dos principais benefícios foi o levantamento das necessidades dos operadores, que eram uma preocupação no início do projeto, dada a baixa escolaridade e familiaridade com tecnologias digitais.

Uma das limitações do estudo foi a impossibilidade de validar a solução por parte de auditores externos, devido a necessidade de melhorar a segurança e contratar uma empresa para tal. Assim, sem essa validação dos auditores, não se pode deixar de utilizar alguns campos do caderno físico, o que impossibilitou avaliar a real economia de papel.

Como estudos futuros propõe-se melhorar a versão inicial com relação a aspectos relacionados à segurança, velocidade, integração com demais bancos de dados e sistemas da empresa, a criação de dashboards para todas as necessidades dos tomadores de decisão e realizar a avaliação de validação por auditores externos.

\section{REFERÊNCIAS}

BALBINOT JUNIOR, A. A.; HIRAKURI, M. H.; FRANCHINI, J. C.; DEBIASI, H.; RIBEIRO, R. H. Análise da área, produção e produtividade da soja no Brasil em duas décadas (1997-2016). Londrina: Embrapa, 2017. 22 p. Disponível em: https://ainfo.cnptia.embrapa.br/digital/bitstream/item/156652/1/Boletim-de-PD11.pdf. Acesso em: 26/04/ 2021.

BROWN, T. Design thinking. Harvard Business Review, v. 86, n. 6, p. 85-92, 2008.

CAMPESE, C.; VANEGAS, C. A. L.; da COSTA, J. M. H. Benefits of the empathy map method and the satisfaction of a company with its application in the development of concepts for a white glue tube. Product: Management \& Development, v. 16, n. 2, 2018. 
CUSTÓDIO, A. F. Modelagem e simulação do processo de separação de óleo de soja-hexano por evaporação. 2003. 247 f. Dissertação (Mestrado em Engenharia Química) - Faculdade de Engenharia Química, Universidade Estadual de Campinas, Campinas, 2003.

DORST, K. The core of 'Design Thinking' and its application. Design Studies, v. 32, n. 6, p. 521-532, 2011.

EMBRAPA. História da soja. 2014. Disponível em: 〈https://www.embrapa.br/soja/cultivos/soja1/historia〉. Acesso em: 13/04/2021.

FIORI, F.C.; BEZERRA, C.A. Relações entre Tipos de Bolsas e Número de Publicações de Bolsistas de Iniciação Científica em Ciências Sociais Aplicadas: Um Estudo na Universidade Federal do Paraná. Revista Administração em Diálogo-RAD, v. 20, n. 1, p. 57-81, 2018.

GONZALES, K.G.; NEVES, T.G.; SANTOS, C.M. Abordagens metodológicas de pesquisa: algumas notas. Revista de Ensino, Educação e Ciências Humanas, v. 19, n. 2, p. 217-226, 2018.

LEMOS, M. L. F.; GUIMARÃES, D. D.; MAIA, G. B. S.; AMARAL, G. F. Agregação de valor na cadeia da soja. In: BNDES SETORIAL: Banco Nacional de Desenvolvimento Econômico e Social. Rio de Janeiro: BNDES, 2017. p. 1-224. Disponível em: http://web.bndes.gov.br/bib/jspui/handle/1408/14114. Acesso em: 26 maio 2021.

NITZCHE, R. Afinal, o que é design thinking? São Paulo: Rosari, 2012.

UNITED NATIONS (ONU). Departament of Economic and Social Affairs, Population Division (2019). World Population Prospects: Highlights. ST/ ESA/ SER.A/ 423, 2019.

PARAÍSO, P. R. Modelagem e análise do processo de obtenção do óleo de soja. 2001. 200 f. Tese (Doutorado) - Faculdade de Engenharia Química, Universidade Estadual de Campinas, Campinas, 2001

SIQUEIRA, A. Persona: como e por que criar uma para sua empresa. 2020. Disponível em: https://resultadosdigitais.com.br/blog/persona-o-que-e/. Acesso em: 27/05/2021.

SILVA, E.R.; SAVARIS, T.; MARCHALEK, A.L.; CASTILHOS, N.C.; TONDOLO, V.A.G. Caracterização das pesquisas de teses em administração com abordagem qualitativa. Revista de Administração de RoraimaRARR, v. 6, n. 1, p. 204-223, 2016.

THIOLLENT, M. Metodologia da pesquisa-ação. São Paulo: Cortez, 2007.

USDA. United States Department of Agriculture: foreign agricultural service. Washington, D.C, 2021. Disponível em: https://apps.fas.usda.gov/psdonline/app/index.html\#/app/compositeViz. Acesso em: 18/04/2021.

VINICIUS, C. O que é briefing e como montá-lo. 2017. Disponível em: https://caiovinnicius.com.br/o-que-ebriefing/. Acesso em: 27/05/2021

WEST-BROOK, R. Action research: a new paradigm for research in production and operations management. International Journal of Operations \& Production Management, 1995. 